\title{
BIELSCHOWSKY HEAD-TILT TEST-I. OCULAR COUNTERROLLING AND BIELSCHOWSKY HEAD-TILT TEST IN 23 CASES OF SUPERIOR OBLIQUE PALSY
}

\author{
H. J. Simonsz,* R. A. Crone, J. van der Meer, C. F. Merckel-Timimer and \\ A. M. van Mourik-NoOrdenbos \\ Department of Ophthalmology, Academisch Medisch Centrum, and the Netherlands Ophthalmic \\ Research Institute, Amsterdam. The Netherlands
}

(Received 19 June 1984; in revised form 14 December 1984)

\begin{abstract}
We have measured the amplitude of ocular counterrolling (OCR) and the change in vertical deviation in the Bielschowsky head-tilt test (BHT) in 23 cases of unilateral superior oblique palsy. OCR was measured with a photographical method, using limbal, conjunctival vessels as landmarks. Average OCR of the healthy eye was $5.4 \pm 2.4$ (SD) deg either side. at 45 deg of body-tilt. BHT and OCR (of the healthy eye) were not related in the group as a whole. An important perturbing factor was the duration of the palsy. To clarify the relation between BHT, OCR and duration of palsy, the BHT OCR ratio was calculated in each patient. Six cases with a palsy of presumed recent onset had BHT/OCR ratio of $0.57 \pm 0.09$, while twelve cases of long-standing palsy had a BHT/OCR ratio of $1.04 \pm 0.71$. This means that in cases of recent onset, the relation was relatively fixed. All high BHT/OCR ratio's occurred in long-standing palsies, whether acquired or congenital. In our opinion, disproportionately large amplitudes in the Bielschowsky head-tilt test are caused by secondary innervational changes or contractures.
\end{abstract}

Ocular counterrolling Bielschowsky head-tilt test movements Strabismus

Cyclotorsion Superior oblique palsy Eye

\section{INTRODUCTION}

The vertical deviation (VD) of the affected eye in superior oblique palsy is augmented by head-tilt toward the affected side and reduced by head-tilt toward the other side. The diagnostic test that employs these alterations in VD of the affected eye is called Bielschowsky head-tilt test (BHT) (Nagel, 1871; Hofmann and Bielschowsky, 1900).

The superior oblique muscle is an intorter as well as a depressor, and the superior oblique, together with the superior rectus, executes the incyclotorsion evoked by head-tilt. Thus, when the superior oblique is paralysed, the eye goes up on head-tilt, by contraction of the superior rectus and inferior oblique, antagonized only by the inferior rectus.

A positive BHT is one of the diagnostic criteria of a superior oblique palsy. Other criteria are an excyclotropia and a VD of the affected eye, that increases on adduction and on infraduction. It is common practice to divide superior oblique palsies in congenital and acquired cases. Indicative of a congenital palsy are, for instance, a tilted head posture during childhood and lack of subjective cyclotropia. Acquired palsies mostly result from blunt head trauma. Often however, no cause is identifiable.

The reflex of in- and excyclotorsion of the healthy

*Oogheelkunde, Academisch Ziekenhuis der Vrije Universiteit, de Boelelaan 1117, 1007 MB Amsterdam, The Netherlands. eye evoked by head-tilt is called ocular counterrolling (OCR). It is effected by alterations in innervational input of otolith-organs to oculomotor nuclei caused by differing direction and magnitude of gravitational force.

Occasionally, a patient with a superior oblique palsy exhibits a very large BHT amplitude. There is a considerable interpersonal variation in the amplitude of OCR, so it would seem logical, that a large BHT amplitude is caused by a large amplitude of naturally occurring OCR, which is the driving force in BHT (see Fig. 1). We have measured the amplitude of BHT and OCR in 23 cases of unilateral superior oblique palsy to see whether these were related. Ten of these cases have been commented upon previously (van der Meer, 1982). We found no relation between BHT and OCR in the group of patients as a whole.

We found, however, that in palsies of presumed recent onset, the ratio between BHT and OCR was relatively fixed. Disproportionately high BHT amplitudes occurred in long-standing cases only, whether congenital or acquired. It seems reasonable to assume, that secondary innervational changes or contractures are responsible for disproportionately high BHT amplitudes.

\section{METHODS}

For OCR measurements we used the method devised by Miller (1962), modified by Howard and Evans (1963). The patient was seated in a chair 


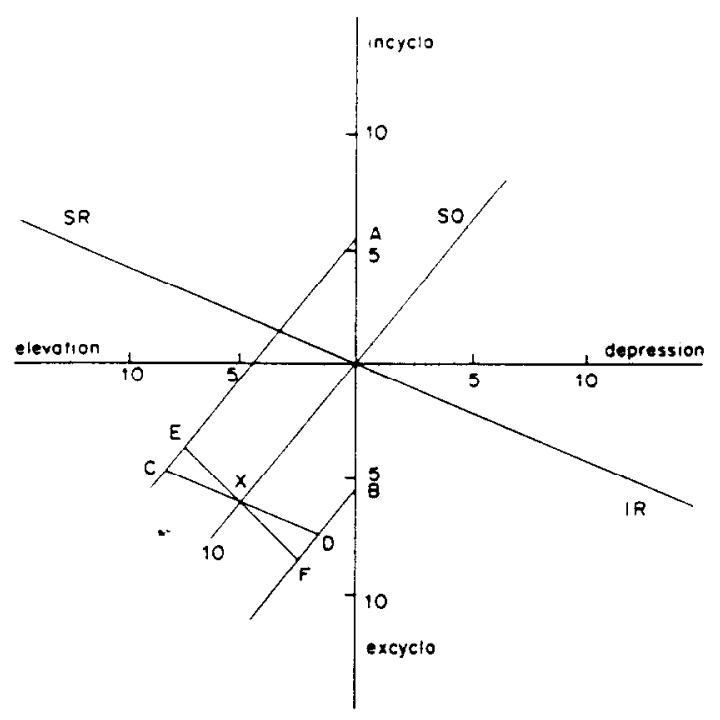

Fig. I. Vector diagram to visualize the relation between BHT and OCR. Ordinate represents torsional eye movement. Abscisse represents vertical eye movement. Vectors of muscle action of superior rectus (SR), inferior rectus (IR) superior oblique (SO) and inferior oblique (IO) are drawn. Points $A$ and $B$ represent the positions the eye assumes in OCR. $5 \frac{1}{3} \mathrm{deg}$ incyclo and $5 \frac{1}{2}$ deg excyclo, on average. If the SO is paralysed, the eye will move in a direction opposite to the SO vector (point $X$ ). The positions the eye will assume on head-tilt will shift in a similar direction (points $E$ and $F$ ). In the case drawn, a VD of $5 \mathrm{deg}$ and an excyclotropia of $6 \mathrm{deg}$ is assumed. What is the path the eye will take in BHT? $C D$ is parallel to the $S R$ and $I R$ vectors. As the IO is still working. EF would then seem a reasonable guess, with a change in VD of $5 \mathrm{deg}$ and a change in excyclotropia of 6 deg. Note that differences in vertical and torsional stiffness of the eye have not been taken into account (Simonsz et al. 1984).

(Fig. 2) mounted on a wall of the room. This chair could rotate about a sagittal axis. 45 deg either way. The frame of the chair extended over and in front of the head of the patient. On the frame a camera with a $200 \mathrm{~mm}$ lens, ring-flash and central fixation-light was mounted, as well as a dental-impression holder, with a thermoplast impression of the teeth. The room was quite dark to preclude optostatic cycloversion (Crone and Everhard-Halm, 1975).

Six series of three pictures were taken: right eye/patient upright-right eye/patient tilted left ear down (excyclotorsion)-right eye/right ear down (inc.) left eye/patient upright-left eye/left ear down (inc.)-left eye/right ear down (exc.).

The diapositive film was projected on a drawing board, with an angle-registration device with vernier. Magnification was about 20 times actual size. Cyclotorsion readings were taken using the most central, limbal, conjunctival vessels as landmarks. A Leitz projector was equipped with a double-reel system to accommodate the entire film, in order to avoid tilt of the projected pictures. From each series of three measurements the average was calculated. Pictures were discarded if displacement of the head had occurred. The displacement was noticed if the eye had moved away from the middle of the picture and by comparison with previous pictures. About $10 \mathrm{sec}$ interval between the taking of the pictures of each series was required for flash recharging. The first picture of each series was taken immediately after tilting the chair. The tilt was performed in about $10 \mathrm{sec}$.

Vertical and horizontal deviations of the affected eye were measured with a red Maddox groove in front of the affected eye, tangent screen with central fixationlight at $2 \frac{1}{2} \mathrm{~m}$ and a spot-projector on a head-band to secure the position of the head. In measuring the vertical deviation of the affected eve, the healthy eye fixated the fixation-light unimpededly, while the affected eye looked through the Maddox groove and hence saw a red horizontal line.

The red line passed through the image of the fixation-light if the eyes were aligned. If, on the other hand, the affected eye deviated upward, the red line would appear below the image of the fixation-light. The place where the red line intersected the ordinate of the tangent screen was reported by the patient.

The measurements were repeated with the head turned 25 deg to the left, right, up and down, resulting in adduction, abduction, infraduction and supraduction of the healthy eye. Finally the measurements were repeated on $45 \mathrm{deg}$ of head-tilt toward the right and left shoulder (Bielschowsky head-tilt test).

Cyclophoria was measured with a Maddox groove that could rotate in a device with a circular scale and a spirit-level that was held horizontally by the examiner. The Maddox groove was rotated until the red line, as seen by the affected eye, appeared parallel to the ordinate of the tangent screen, while the other eye was uncovered.

All patients were diagnosied by one of the authors (R.A.C.) as cases of superior oblique palsy, between July 1980 and December 1983. Ten cases were right palsies, 13 cases were left palsies. All patients had a VD of the affected eye, in all cases increasing on head-tilt toward the affected side (BHT), in all cases increasing in adduction, and in 17 cases increasing in infraduction. Children under 10 years of age were excluded from the study, as well as disabled and edentate patients.

\section{RESLLTS}

Patient number, date of onset of complaints and essential history are given in Table 1. Patient number, date of birth, affected eye, OCR, deviations of the affected eye with the healthy eye in primary position, subjective cyclophoria, VD's in various gaze-positions and on head-tilt (BHT) are given in Table 2. The measurements are preceded by the date of their collection, in parenthesis. Not all measurements of horizontal, vertical and cyclo deviations are shown. That set of measurements was selected that was closest in date to the OCR measurement. Contrariwise, all BHT measurements are shown. VD's are 


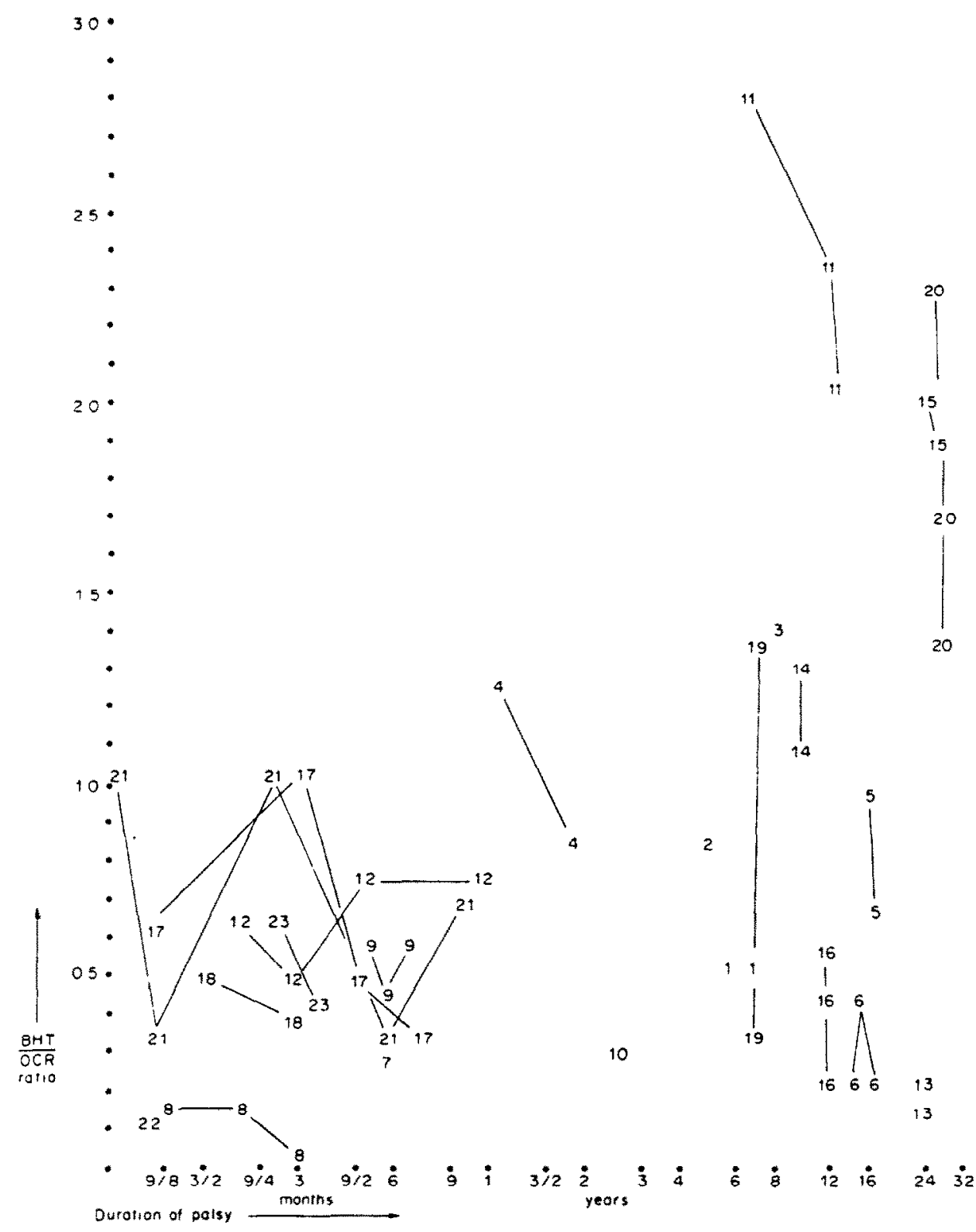

Fig. 2. Relation between BHT, OCR and duration of palsy. For each BHT measurement, the BHT/OCR ratio was calculated, using the total $O C R$ of the healthy eye as denominator. Note that $O C R$ was measured only once, while BHT was measured several times in some patients. The BHT/OCR ratio is represented by the ordinate, the duration of the palsy is represented by the abscissa, in months and years. Duration of the palsy applies to the interval between onset of palsy and BHT measurement. It is irrespective of the date of OCR measurement. Patient-numbers connected by lines represent several BHT measurements in one patient with one total OCR measurement as denominator in the BHT/OCR ratio. The duration of the palsy is represented by a logarithmical scale, to accommodate all data conveniently. The duration of the palsy is expressed in months and years, respectively.

shown for the following gaze-positions of the healthy eye: $25 \mathrm{deg}$ right $/ 25 \mathrm{deg}$ left, $25 \mathrm{deg}$ up $/ 25 \mathrm{deg}$ down and $25 \mathrm{deg}$ adduction-and-up/25 deg adduction-anddown. Two cases, initially diagnosed as cases of superior oblique palsy, were excluded from the study because of uncertainty about the diagnosis. One had a large concomitant vertical deviation, the other had a vertical deviation that decreased on adduction. No other cases of unilateral superior oblique palsy were observed.
Averaged data are shown in Table 3. To clarify the relation between $B H T$, OCR and duration of the palsy, the BHT/OCR ratio was calculated for each BHT measurement, using the total OCR of the healthy eye in each patient as denominator. These ratios are represented graphically in Fig. 2 by the ordinate. Duration of the palsy is represented logarithmically on the abscissa. As apparent from Fig. 2, the patients fell into two groups, consisting of recent and long-standing cases. So two subsets of 
Table 1. Patient number and essential patient data

\begin{tabular}{|c|c|c|}
\hline $\begin{array}{l}\text { Patient } \\
\text { number }\end{array}$ & $\begin{array}{l}\text { Date of onset } \\
\text { of complaints }\end{array}$ & Essentials of history \\
\hline 1 & 1974 & Spontaneous onset of diplopia; sustained commotio in 1968: tort + . ster - \\
\hline 2 & 1975 & Car-accident: 3 weeks in coma, tort + \\
\hline 3 & Cong & Ton + \\
\hline 4 & 1979 & Car-hood hit head; tort + , ster + \\
\hline 5 & 1964 & 3 weks in coma after skull-base fracture; tort - \\
\hline 6 & Cong & Vertugo for years; tort + . ster - \\
\hline 7 & 5.10 .50 & $\begin{array}{l}\text { Fallen in bath on left side of face: complained. paradoxicully of periods of diplopia on head-tilt to right } \\
\text { shoulder. while left sup obl was affected }\end{array}$ \\
\hline 8 & 18.1 .81 & Hit in fight, for a while unconscious: spontantous resolution: tort + \\
\hline 9 & 8.80 & Spontaneous onset; fallen on right eye brow in 1974: tort + \\
\hline 10 & 10.78 & Spontaneous diplopia, in a few weeks progressive; sustained commotio in remote past \\
\hline II & 1969 & Fallen: tort.+ ster + \\
\hline 12 & 6.81 & $\begin{array}{l}\text { Fallen on face; tort }- \text { ster }+ \text { : complained also of diplopia after car-idcident. } 3 \text { years previously, but } \\
\text { then spontaneous resolution occurred }\end{array}$ \\
\hline 13 & 1958 & Car-accident; tort + , ster + \\
\hline 14 & Cong & Tort + \\
\hline 15 & Cong & Tort since 1980; in 1961 "convergence insufficience" diagnosed elsewhere \\
\hline 16 & 1970 & Commotio; tort + \\
\hline 17 & 4.82 & Hit by twig in eye, spontaneous resolution, tort + , ster - \\
\hline 18 & 31.8 .82 & Door-knob in eye \\
\hline 19 & 1975 & Diplopia started after "influenza" \\
\hline 20 & Cong & Tort + \\
\hline 21 & 1.82 & Unknown cause; tort + \\
\hline 22 & 20.9.82 & Herpes zoster; spontaneous resolution \\
\hline 23 & 1.8 .83 & Unknown cause; tort + \\
\hline
\end{tabular}

"Tort" denotes torticolis: "ster" denotes stereopsis; "cong" denotes congenital.

patients were composed. Patients $9,12,17,18,21$ and 23 all had a superior oblique palsy of recent onset, first seen within six months. Patients 7,8 and 22 were excluded from this group for reasons mentioned in the discussion section. Patients $1,2,3,5,6,11,13,14$, 15, 16, 19 and 20 all had a long-standing palsy, first seen more than 5 years after onset. Because of the arbitrarily set limits of 1 and 5 years, patients 4 and 10 were entered into neither subset.

In the first nine patients, OCR was measured not only after body-tilt, but also after head-tilt, to quantify the influence of tonic neck-reflexes. The difference proved to be small, $0.25 \pm 1.39 \mathrm{deg}$, head-tilt yielding more OCR ( $n=18=2 \times 9$ healthy eyes). Similarly, in 16 healthy volunteers, we found a difference in OCR between head-tilt and body-tilt of $0.43 \pm 1.07$ deg, body-tilt yielding more OCR; their OCR was $5.33 \pm 1.72$ excyclo and $5.71 \pm 2.17$ incyclo, on a 45-deg body-tilt ( $n=64=2 \times 32$ healthy eyes). Because the difference was small and fixation of the head could not be controlled as accurately in head-tilt as opposed to body-tilt, the method was abandoned.

Each OCR figure in Table 2 is the average taken from three measurements. These measurements are not shown individually. The difference between the second measurement minus the first measurement was $+0.2 \pm 0.8 \mathrm{deg}$. The difference between the third measurement minus the second measurement was $+0.0 \pm 0.8 \mathrm{deg}$

\section{DISCUSSION}

We found no relation between BHT and OCR in the group of 23 patients as a whole. Interfering factors were searched for. The duration of the palsy proved to be an important perturbing factor. In
Fig. 2 the relation between BHT, OCR and duration of the palsy is depicted. The clustering of BHT/OCR ratios of patients with a superior oblique palsy of recent onset around 0.57 is conspicuous. Other interfering factors could be:

(a) Patient selection. The group is biased toward cases with problems in diagnosis, because these cases will preferentially be referred to a University Clinic. The problem in diagnosis might be related to an abnormal BHT/OCR ratio.

(b) Patient 8 and 22 had an incomplete, quickly resolving palsy. This might have been the case in other patients too. In some apparently complete palsies, electromyographical activity can be registered in the superior oblique muscle (A. B. Scott, personal communication).

(c) Patient 7 probably had a trochlear lesion. He complained of periods of diplopia on head-tilt toward the right shoulder, while the left superior oblique was affected. It is possible that the tendon of the left superior oblique was not entirely free to move through the trochlea, as a result of the trauma to the left orbit.

(d) Differing angles between superior oblique tendon and sagittal plane. According to Fink (1950), this angle may vary considerably from person to person. The larger the angle, the less BHT per OCR.

(e) Tonic neck-reflex. OCR was measured on bodytilt, while BHT was measured on head-tilt. We found, however, little difference between $O C R$ on head-tilt and OCR on body-tilt.

(f) Cycloversion and -vergence do occur spontaneously, up to 1 degree (Diamond et al., 1982). This may have influenced the OCR measurements slightly.

(g) From the work of Nelson and Cope (1971), it can be seen that OCR amplitudes of yoke eyes in 


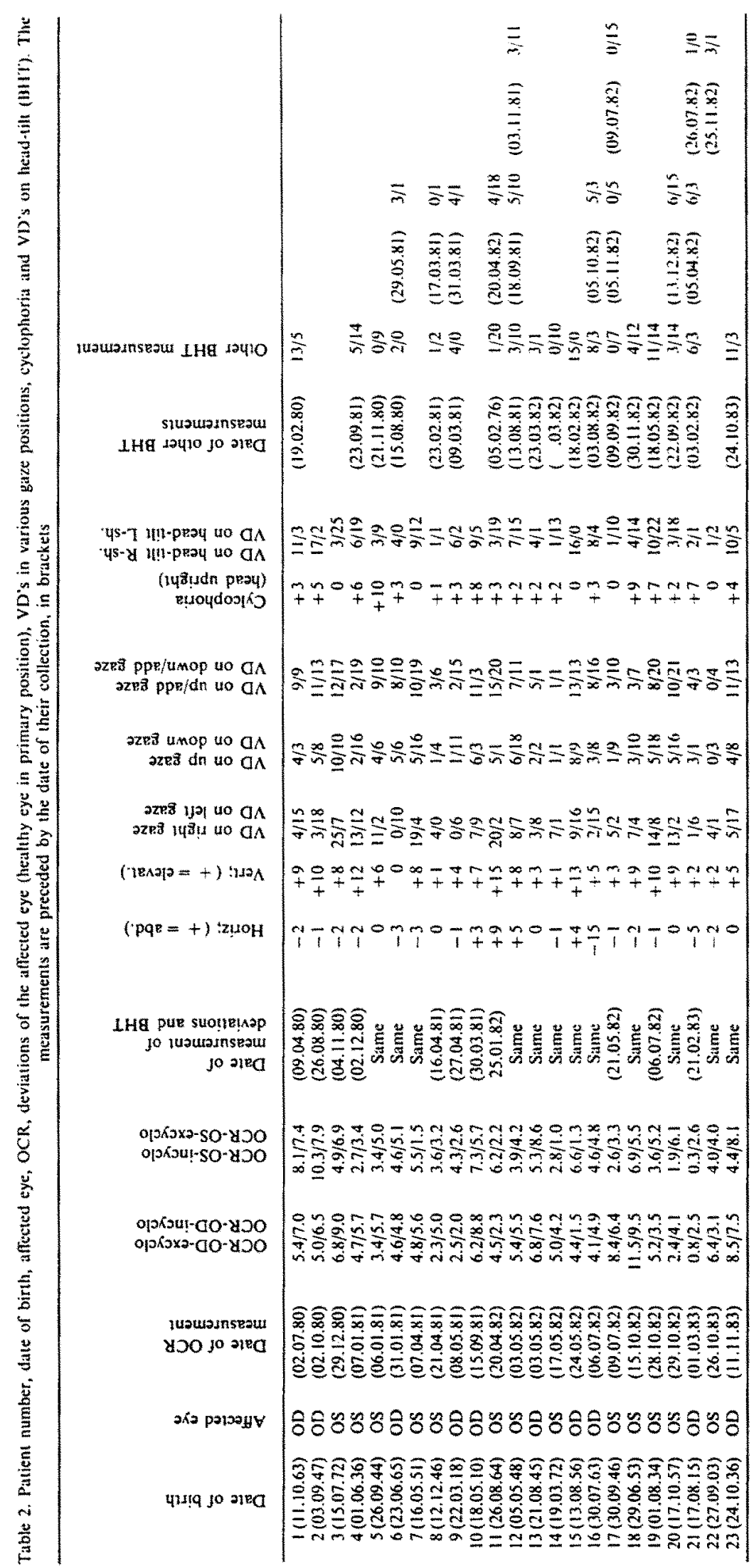


Table 3 . Average OCR, VD. alterations in VD in BHT and various gaze-positions, BHT OCR ratio and subjective cyclophoria in all patients and in two subsets of patients comprising palsies of recent onset (shorter than 1 yeat) and long-standing palsies tlonger than 5 years)

\begin{tabular}{|c|c|c|c|}
\hline & All Patients & $\begin{array}{l}\text { Patients } \\
9.12 .17 .18 .21 .23 \\
\text { irecent-onset pulst }\end{array}$ & $\begin{array}{l}\text { Patients } 1,2,3,5,6 . \\
11,13,14,15,16,19 \\
\text { long-standing palsy }\end{array}$ \\
\hline $\begin{array}{r}\text { Average } O C R \text { of the healthy eye. excyclo: } \\
\text { incyclo: } \\
\text { total: }\end{array}$ & $\begin{array}{r}5.43 \pm 2.47 \\
5.45 \pm 2.32 \\
10.88 \pm 4.19\end{array}$ & $\begin{array}{l}6.4=3.51 \\
5.07=501\end{array}$ & $\begin{array}{l}5.20=2.20 \\
5.69=2.38\end{array}$ \\
\hline $\begin{array}{l}\text { Average, absolute difference between ex- and } \\
\text { incyclo OCR. healthy eye: }\end{array}$ & $1.93 \pm 1.23$ & & \\
\hline $\begin{array}{r}\text { Average OCR of the affected eye. excyclo: } \\
\text { incyclo: } \\
\text { total: }\end{array}$ & $\begin{array}{l}4.34 \pm 1.95 \\
4.57 \pm 2.09 \\
8.91 \pm 3.51\end{array}$ & $\begin{array}{l}4.13=2.67 \\
+.23=2.39\end{array}$ & $\begin{array}{l}4.72=1.72 \\
+.59=1.99\end{array}$ \\
\hline $\begin{array}{l}\text { Average, absolute difference between ex- and } \\
\text { incyclo OCR, affected eye }\end{array}$ & $1.58+1.23$ & & \\
\hline $\begin{array}{l}\text { Average VD (healthy eye in primary position): } \\
\text { Average difference of VD on head-till toward } \\
\text { affected side minus VD on head-tilt toward }\end{array}$ & & $5.17=2.79$ & $7.4 \pm=4.58$ \\
\hline $\begin{array}{l}\text { healhy side ( = BHT) } \\
\text { BHT (averaged per patient) divided by total } \\
\text { OCR of the healthy eye in each patient }\end{array}$ & & $5.86 \pm 2.55$ & $10.06=5.79$ \\
\hline $\begin{array}{l}(=\text { BHT OCR ratio): } \\
\text { Average difference on VD on } 25 \text {-deg adduction }\end{array}$ & & $0.57 \pm 009$ & $1.04=0.71$ \\
\hline $\begin{array}{l}\text { minus } 25-\mathrm{deg} \text { abduction: } \\
\text { Average difference of VD on } 25 \text {-deg down gaze }\end{array}$ & & $5.00 \pm 3.35$ & $10.75 \pm 4.52$ \\
\hline $\begin{array}{l}\text { minus } 25-\text { deg up gaze: } \\
\text { Average difference of VD on } 25 \text {-deg down-and- }\end{array}$ & & $6.50 \pm 4.97$ & $2.58 \pm 4.92$ \\
\hline $\begin{array}{l}\text { adducted gaze minus } 25 \text {-deg up-and-adducted gaze } \\
\text { Average (subjective) cyclophoria: }\end{array}$ & & $4.83 \pm 4.79$ & $3.50 \pm \$ .83$ \\
\hline Average (subjective) cyclophoria: & & $4.17 \pm 3.31$ & $3.33 \pm 2.84$ \\
\hline
\end{tabular}

All figures are in degrees. I Denote standard deviation. It should be borne in mind. that "Average OCR of the affected eye" as mentioned in the table, is not an entirely correct designation of the measurement that was performed. What was measured was torsion of the eye about the line of sight, accomplished by 5 normal and I paretic muscle. Moreover, ex-and incyclotorsion is measured from an excyclo starting position, which we cannot determine with certainty, as subjectively mesured cyclophoria does not necessairly conform to objective cyclophoria (Guyton and von Noorden. 1978).

healthy persons may differ considerably. In the 35 healthy volunteers of the study of Neison and Cope the difference amounted to $2.51 \pm 2.28 \mathrm{deg}$. This finding depreciates the $\mathrm{BHT} / \mathrm{OCR}$ ratio to some extent.

In Table 3 averaged data are given separately for patients $9,12,17,18,21$ and 23 , all cases of superior oblique palsy of presumed recent onset. Patients 7,8 and 22 were excluded from this group for reasons mentioned above. Averaged data are also given for patients $1,2,3,5,6,11,13,14,15,16,19$ and 20 , comprising a group of long-standing palsies. Apart from a greater variability in BHT/OCR ratio, the latter 12 patients had, on average, smaller differences in VD on up and down gaze (secondary concomitance), but larger differences in VD on ad- and abduction.

From this study it appears that the relation between BHT and OCR is relatively fixed in palsies of recent onset. It seems reasonable to assume that high BHT/OCR ratio's, i.e. disproportionately large BHT amplitudes, are caused by secondary innervational changes or contractures.

Acknowledgements - We would like to thank Professor D. A. Robinson and Professor G. Kommerell for their encouragement and valuable comments. We would like to thank Stella R. Ompi for art-work.

\section{REFERENCES}

Crone R. A. and Everhard-Halm Y. (1975) Optically induced eye torsion. II. Optostatic and optokinetic cycloversion. A. $r$. Graefes Arch. klin. exp. Ophthal. 195. $231-239$.

Diamond S. G., Markham C. H. and Furaya N. (1982) Binocular counterrolling during sustained body tilt in normal humans and in a patient with unilateral vestibular nerve section. Ann, Otol. 91, 225-229.

Guyton D. L. and von Noorden G. K. (1978) Sensory adaptations to cyclodeviations. Proc. Third Meet. Int. Strab. Assoc.. Kyoto (Edited by Reinecke R. D.), pp. 339-403. Grune \& Stratton, New York.

Hofmann F. B. and Bielschowsky A. (1900) Dit Verwerthung der Kopfneigung zur Diagnostik von Augenmuskellähmungen aus der Heber- und Senkergruppe. $A$. v. Graefes Arch. Ophthal. 51, 174-185.

Howard I. P. and Evans J. A. (1963) The measurement of eye torsion. Vision Res. 3, 447-455.

van der Meer J. (1982) The Bielschowsky head tilt test and ocular counterrolling. Documenta ophth. Proc. Ser. 32, 179-184.

Miller E. F. (1962) Counterrolling of the human eyes produced by head tit with respect to gravity. Acta otolor. $54,479-501$.

Nagel A. (1871) Über das Vorkommen von wahren Rollungen des Auges um die Gesichtslinie. A. $t$. Graefes Arch. Ophthat. 17, 237-264.

Nelson J. R. and Cope D. (1971) The otoliths and the ocular countertorsion reflex. Archs Otolar.. Stockh. 94, 40-50.

Simonsz H. J., Crone R. A. de Waal B. J., Schooneman M. and Lorentz de Haas H. A. L. (1984) Measurement of the mechanical stiffiness in cyclotorsion of the human eye. Vision Res. 24, 961-968. 